\title{
POINTS AND STUDENT MOTIVATION
}

\author{
by Barbara Pflanz
}

University of Redlands

Student motivation and learning go hand in hand, as many writers have pointed out. Since the primary goal of the educator is to produce learning, how then, can one achieve motivation in the learner? Motivation is certainly not the result of any one aspect of a course or of the teaching. In addition to teaching techniques, the subject matter and even instructor personality can be factors in student motivation. It will be suggested here that another aspect, namely, the evaluation system, can play an important role in the motivation of students to learn.

"He gave me a 2.7" is a comment heard not infrequently when semester grades come out. Probably no instructor likes to hear that she/he "gives" grades; students earn grades, but they sometimes seem to feef that the evaluation has not always been arrived at as a direct result of their efforts. And in some cases that may even be true. A solution to this for both student and instructor would seem to be a carefully-structured grading system whereby the student can accurately monitor her/his progress during the semester. With such a system the grade is seen fluctuating as a direct result of student effort and achievement and not as an end-of-semester decision by the instructor, based on a few tests and a final examination. Student motivation, usually highest only before a final testing, could thus be maintained at a high level throughout the grading period.

In an attempt to create such a situation the author developed a point system for grading and evaluation in German language courses at the University of Redlands. The system functions as follows:

1. Structure: In the syllabus which describes the goals and structure of the course, the following section explains the system of evaluation.

The evaluation of your work will be based on a point system with a total of 1500 possible points distributed as follows:

\author{
8 vocabulary tests \\ 8 short tests \\ 2 films \\ 3 semester tests \\ classwork \\ final examination
}

$$
\begin{aligned}
& 20-30 \text { points each } \\
& 20-50 \text { points each } \\
& 30 \text { points each } \\
& 200 \text { points each } \\
& 100 \text { points } \\
& 300 \text { points }
\end{aligned}
$$


Your final grade will depend upon the total number of points you have achieved. The percentages of this system are given in parentheses:

$$
\begin{aligned}
& 1440-1500=4.0(96-100) 1215-1259=2.7(81-83) 990-1049=1.3(66-69) \\
& 1380-1439=3.7(92-95) \quad 1155-1214=2.3(77-80) 930-989=1.0(62-65) \\
& 1320-1379=3.3(88-91) \quad 1095-1154=2.0(73-76) 885-929=0.7(59-61) \\
& 1260-1319=3.0(84-87) \quad 1050-1094=1.7(70-72) \quad 0-884=\text { No Credit }
\end{aligned}
$$

2. Testing instruments: The syllabus provides a calendar for the entire semester listing all evaluating instruments and their point value. Here is an example for a two-week period occurring in mid-semester. The numbers in parentheses give the point value of the test or activity.

\section{DATE}

17 October

19 October

25 October

27 October

28 October

\section{CLASSWORK}

Vocabulary test

Film

Test: Lesson V

Vocabulary test

Test: Lesson VI

2. Semester test
(20)

(200)

3. Point totals: As a convenience for keeping a running total of points achieved (and as an incentive to do so), the following chart is provided in the syllabus. Sample entries here show how the student enters and

\begin{tabular}{|c|c|c|c|c|c|c|c|}
\hline DATE & 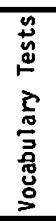 & 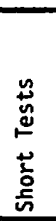 & 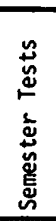 & $\frac{\underline{\underline{E}}}{i}$ & 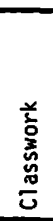 & 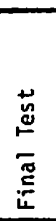 & TOTAL \\
\hline 16. September & 15 & 8 & & & & & 15 \\
\hline 19. " & 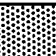 & 18 & & & & & \begin{tabular}{|l|}
18 \\
33 \\
\end{tabular} \\
\hline 23. & 17 & & & & & & $\frac{27}{50}$ \\
\hline 30. " & & 21 & & & & & $-\frac{21}{71}$ \\
\hline 3. October & 12 & & 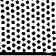 & & & & \begin{tabular}{|l}
12 \\
63 \\
\end{tabular} \\
\hline $6 . \quad 11$ & & & 165 & & & & \begin{tabular}{|l}
165 \\
248 \\
\end{tabular} \\
\hline & & & & & & & \\
\hline
\end{tabular}
tallies her/his point total. The dates given are those on which tests are returned to the student.

Figure 1 
4. Evaluation Chart: By using the following table (Figure 2) the student can determine her/his grade on any date given in the heading of each column. These dates represent days on which tests are returned to the students and correspond to the dates on the preceding chart (Figure 1). The number in parentheses under each date in Figure 2 represents the total possible on that day. The table begins with 30 September, since the total number of points that could be attained before that date is too small to be of significance in starting an overall grade. Example: the fictitious student whose grades were entered on the chart (Figure 1) achieved a total of 248 points on 6 October. In the table (Figure 2) under the column for 6 October this falls in the range 239-250. Reading from the first column on the left, the grade is found to be 2.3 .

Figure 2

\begin{tabular}{|c|c|c|c|c|c|c|}
\hline DATUM & $\begin{array}{c}30 . I X \\
(90)\end{array}$ & $\begin{array}{c}3 . X \\
(110)\end{array}$ & $\begin{array}{c}6 . X \\
(310)\end{array}$ & $\begin{array}{c}11 . X \\
(330)\end{array}$ & $\begin{array}{c}14 . X \\
(360)\end{array}$ & $\begin{array}{c}18 . X \\
(410)\end{array}$ \\
\hline 4.0 & $86-90$ & $106-110$ & $298-310$ & $317-330$ & $346-360$ & $394-410$ \\
\hline 3.7 & $83-85$ & $101-105$ & $285-297$ & $304-316$ & $331-345$ & $377-393$ \\
\hline 3.3 & $79-82$ & $97-100$ & $273-284$ & $290-303$ & $317-330$ & $361-376$ \\
\hline 3.0 & $76-78$ & $92-96$ & $260-272$ & $277-289$ & $302-316$ & $344-360$ \\
\hline 2.7 & $73-75$ & $89-91$ & $251-259$ & $267-276$ & $292-301$ & $332-343$ \\
\hline 2.3 & $69-72$ & $85-88$ & $239-250$ & $254-266$ & $277-291$ & $316-331$ \\
\hline 2.0 & $66-68$ & $80-84$ & $226-238$ & $241-253$ & $263-276$ & $299-315$ \\
\hline 1.7 & $63-65$ & $77-79$ & $217-225$ & $231-240$ & $252-262$ & $287-298$ \\
\hline 1.3 & $59-62$ & $73-76$ & $205-216$ & $218-230$ & $238-251$ & $271-286$ \\
\hline 1.0 & $56-58$ & $68-72$ & $192-204$ & $205-217$ & $223-237$ & $254-270$ \\
\hline 0.7 & $53-55$ & $65-67$ & $183-191$ & $195-204$ & $212-222$ & $242-253$ \\
\hline
\end{tabular}

(Datum $=$ date $\quad$ Note $=$ grade $)$

The following formula was used to determine the lower range for each grade in the table: total points possible on given date $x$ lower percent grade figure. For example, on 6 October the total points possible is 310 . The lower figure of the range for the grade of $2.3(77 \%-80 \%)$ is thus: $310 \times 77=239$. The upper range for that grade is one point less than the lower range for the preceding grade. In the case of the 4.0 grade this top figure is, of course, the total points possible.

The advantages and disadvantages of this system of evaluation can be summarized as follows: 


\section{A. Advantages:}

1. The student can determine her/his grade with a high degree of accuracy before and after each test; in the author's classes this possibility occurs Iwenty or more times during the thirteen-week semester. Thus the motivation usually present only before a final test, is generated at all testing times.

2. The student can early detect when she/he is not performing up to her/his expectations and request assistance.

3. Since the student can at all times see how she/he is progressing and also review the results of previous efforts and how these effected her/his present level of achievement, the stigma of a subjective grade is removed from the instructor. The student sees herself/himself as almost totally repsonsible for the grade received.

4. As a result of 3 , the student under this system usually takes more of the responsibility for achieving learning.

\section{B. Disadvantages:}

1. The system requires a relatively high degree of organization and planning on the part of the instructor. For it to function effectively the instructor must: a. plan the entire semester (at least the tests and other evaluative instruments) in advance and make his information available to the student at the beginning of the semester; b. accept the responsibility for making known test results on the designated days; c. exercise great care in selting up the system since the possibility of mathematical error is quite high; d. (if the course is to use such testing instruments as the essay-type question) be willing to objectify her/his evaluation of such questions.

2. Due to a built-in arrangement for make-up tests at semester's end, and the varying number of points assigned to the vocabulary tests and the short tests, the grade chart is slightly inaccurate. The degree of error here is, however, insignificant. In addition, a simple mathematical formula can be used to compute grades when tests have been missed.'

\section{Conclusion}

After using the above-described point system in seven courses the author has judged it to be far superior to the usual system of assigning a percentage grade to each test and weighting these to arrive at the final grade. In the author's opinion, the high degree of student motivation and 
concern for her/his own progress far outweights the initial burden of preparation placed on the instructor. Some might call the system a "numbers game". Perhaps it is. But if this "game" produces a learningmotivated student throughout the semester, if it changes the role of the instructor from "grade-giver" to "learning assistant", what does it matter what you call it?²

\section{FOOTNOTES}

'This formula for any given day is:

$$
\text { the percentage grade }=\frac{P}{T-25 V-32 S} \times 100
$$

where $P$ is the total possible points for the given day, $T$ is the student's total points on that day, $V$ is the number of vocabulary tests missed and $S$ the number of short tests missed.

${ }^{2}$ For anyone interested in developing such a point system for their own courses, the author will be happy to provide a copy of the course syllabus described in this article. Please send a self-addressed, stamped envelope to: Dr. Barbara Pflanz, Department of German. University of Redlands, Redlands, California 92373

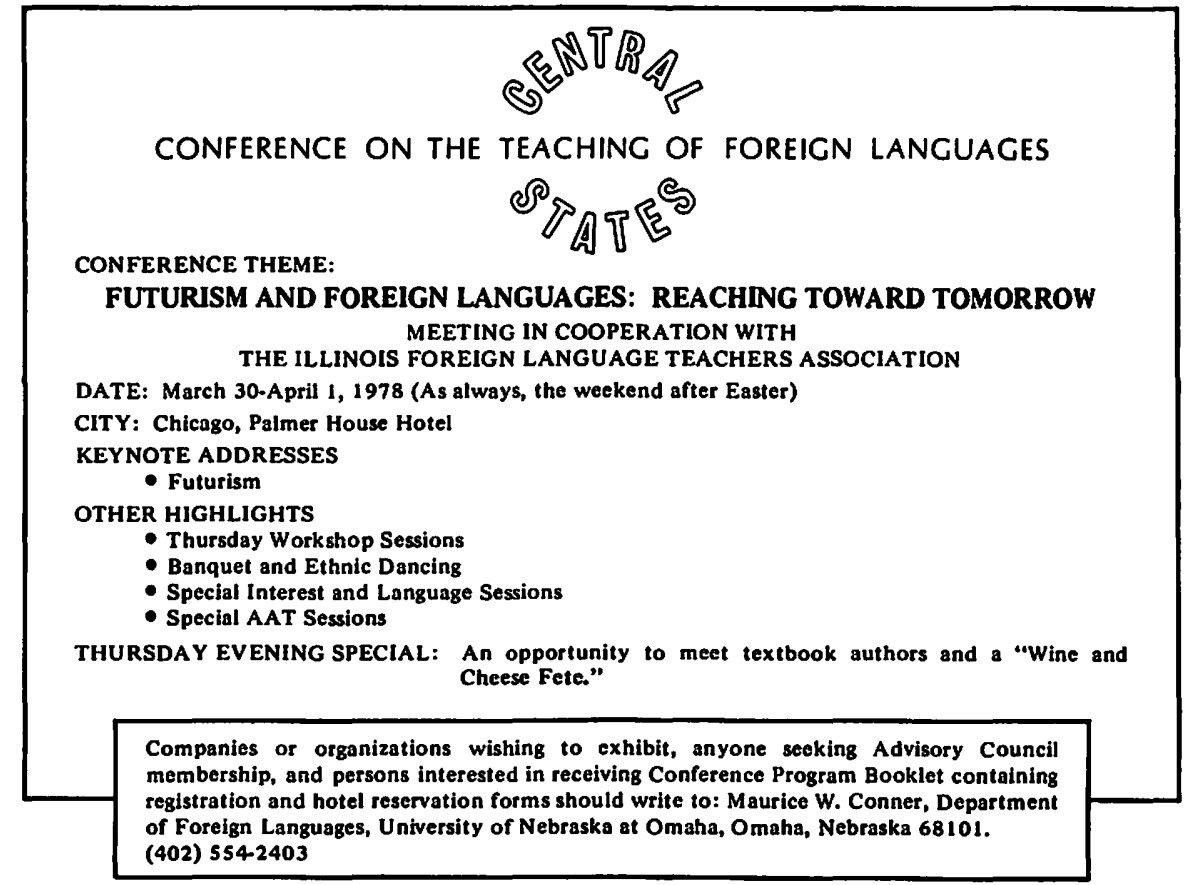

